www. revistadyo.com

\title{
Intellectual Capital and Balanced Scorecard: impact of Learning and Development Programs using Key Performance Indicators in Manufacturing Environment
}

\author{
Sanchez-Marquez R , Albarracin Guillem JM , Vicens-Salort E , José Jabaloyes Vivas
}

Recibido: 1 de Marzo de 2018 / Aceptado: 27 de Abril de 2018

\begin{abstract}
Within the current context, the Intellectual Capital has been unveiled as one of the Key drivers for companies' long-term profitability and sustainability. This paper proposes a new methodology using Key Performance Indicators (KPIs) from the Balanced Scorecard of a Manufacturing Company to confirm the impact of Learning and Development Programs in the actual performance of the organization. Statistical Multivariate and Multiple Regression techniques are applied as a systemic approach using KPIs to firstly analyze and confirm the impact of Learning \& Development and secondly to design the best strategy for short term financial results and long term sustainability. The proposed methodology was applied in a Manufacturing Company to confirm its validity in practical terms.
\end{abstract}

\section{Keywords}

Intellectual Capital (IC), Learning \& Development Programs (L\&DPs), Key Performance Indicators (KPIs), Decision Making, Performance Management System (PMS), Competence

\section{Introduction}

Kaplan and Norton's Balanced Scorecard theory and tools (Kaplan and Norton 1992) have become the most extended method to manage performance especially in large organizations, regardless some of its limitations and issues addressed in some studies (Knoerreklit and Schoenfeld 2000).

The use of the Balanced Scorecard (BSC) as a Performance Management System (PMS), and its main objective that is to translate strategy into specific actions has been studied in many research works (Kaplan and Norton 1996a, b; Kaplan 2009; Otley 1999; Rodriguez-Rodriguez et al. 2009, 2014; Verdecho et al. 2014). The validity and effectiveness of its

Rafael Sánchez Márquez *
rsanch18@ford.com
José Miguel Albarracín Guillem **
jmalbarr@omp.upv.es
Eduardo Vicens-Salort ***
evicens@cigip.upv.es
José Jabaloyes Vivas ****
jabaloye@eio.upv.es
* Lean Coach \& 6 Sigma MBB, U.P.V. Doctorate Student
** Departamento de Organización de Empresas, Universitat
Politècnica de València.
*** Production Management and Engineering Research
Centre, Universitat Politècnica de València
**** Department of Statistics, Operational Investigation and
Quality, Universitat Politecnica de Valencia

scientific use combined with analytic and different systemic methods has been confirmed in several research works (Rodriguez-Rodriguez et al., 2009; Boj et al., 2014; SanchezMarquez et al., under review).

The importance of the Intellectual Capital (IC) within the human organizations in the current competitive and changing environment has been widely studied and/or confirmed in several studies (Stewart \& Ruckdeschel, 1999; Nahapiel and Ghoshal, 1998; Teece DJ, 2000; Delios and Beamish, 2001; McGaughey, 2002; Chang et al., 2008; Kaufmann and Schneider, 2004).

Thus, those works have denoted the importance of IC as a driver, even as a measurement of organizational performance. Nevertheless, the merge of IC metrics and BSC as a system has been proved effective and its use with analytical and systemic tools is thoroughly proved and confirmed by Boj JJ et al. (2014).

As IC has been defined as knowledge, talents and skills suitable to be used to create wealth (Stewart \& Ruckdeschel, 1998; Jurczak J, 2008) and Learning and Development Programs (L\&DPs) is the key tool to acquire new competences, the assessment of effectiveness of L\&DPs within the organizations is key for success. Organizations invest on L\&DPs with funds and internal resources to increase the so-called IC to improve their competitiveness, thus a scientific and robust method to assess its effectiveness is even more necessary.

Despite some contemporary issues addressed by scholars (Morcke et al., 2012; Pijl-Zieber et al., 2013; ten Cate, 2013; Norman et al., 2014), competency-based education programs, mainly due to its linkage to learning and devel- 
opment, have been adopted by many organizations and even countries (Mirabile, 1997; Brodersen et al., 2017; Johnstone \& Soares, 2014; Sturgis et al., 2011). A competency thus can be defined as "a set of observable behaviors acquired through knowledge, skills and experiences that contribute to successful work accomplishments" and IC as "knowledge, talents and skills suitable to be used to create wealth". The relationship between competence and IC then becomes obvious. Since the former relates to the individuals, the latter could be partially referred to as the amount of competences of the individuals who form an organization, although not limited only to that.

The learning outcome is a key concept within both competence and IC. Morcke et al. (2012) have also pointed out the lack of empirical evidence in the scientific literature. Our research work focuses on providing empirical evidence of the creation of wealth from L\&DPs with specific outcomes aligned to business objectives and strategies. Therefore, it addresses some of the gaps from previous works and at the same time providing a method with a clear link between IC, competencies and the BSC.
This paper is presenting the development and application of a method to assess the effectiveness of L\&DPs within manufacturing environment. The method is developed and applied in a manufacturing company as a case study approach to confirm the previous theories and the proposed method validity by itself.

The main input of this work to the current knowledge is the application of a new method in manufacturing environment using actual data. Although other methods and studies have been carried out, there is a lack of works in manufacturing environment using actual data to assess the effectiveness of L\&DPs as a tool to improve people competence and thus IC of the company as a key asset.

With the application of this method, we also seek to confirm through empirical evidence the relationships and mechanisms, which connect concepts proposed by authors from different fields such as BSC, Competency-based education, Intangible Assets (IA) and IC that could be explained by the concept map shown on figure 1 just below.

Figure 1 Concept Map. Internal mechanisms of the organization

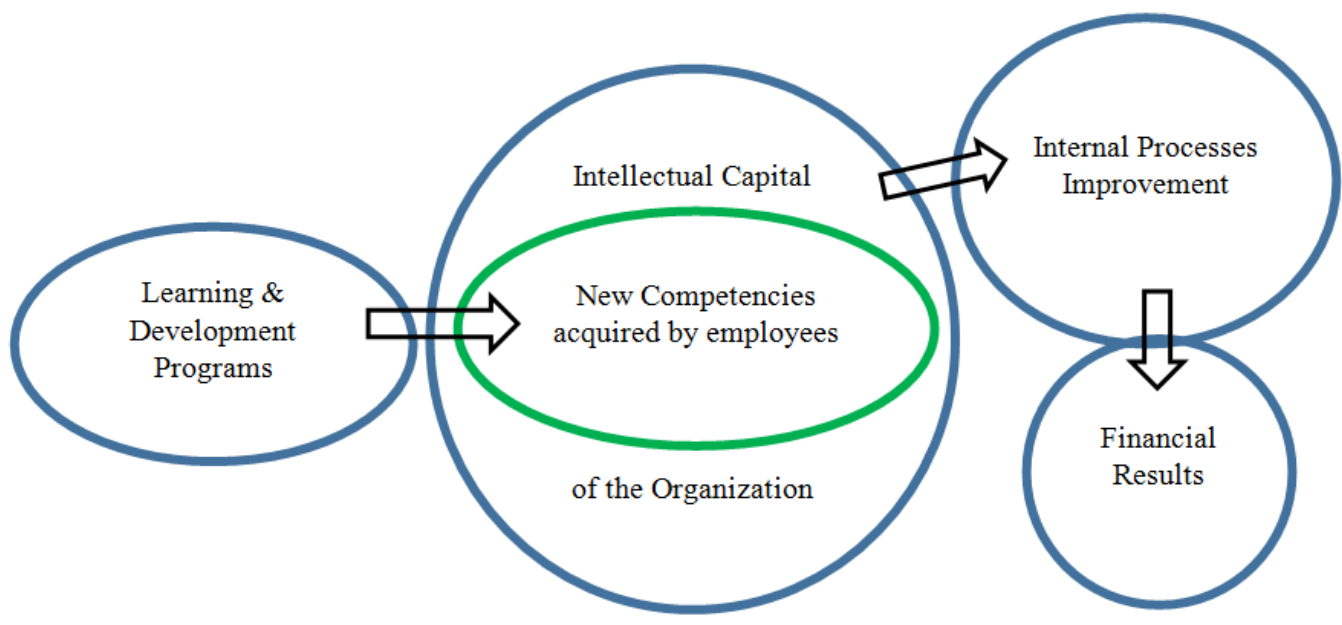

\section{Literature Review}

As seen in the previous section, the main aim of this paper is to develop and apply a methodology to assess L\&DPs effectiveness as a managing tool to improve IC and thus company performance in the manufacturing environment using actual data and Key Performance Indicators (KPIs).

Due to the lack of research work in the manufacturing context, other environments have been also explored during literature review to gain knowledge about related and potentially applicable methods for our purpose.

A literature review has been performed using three scientific search engines, which are Scopus, Web of Science and Google Scholar. Main topics focused on the search were:
- $\quad$ Balanced Scorecard (BSC) as a Performance Management System (PMS)

- $\quad$ KPIs selection methods on BSC

- Analytical Methods to select KPIs and define strategies

- $\quad$ Time series analysis and treatment methods

- $\quad$ Intellectual Capital and Intangible Assets

- $\quad$ Competency-based educational programs 
Large companies and especially multinational ones, as it is our case-study company, normally use BSC approach as mentioned by Knoerreklit and Schoenfeld (2000) as PMS. Its effectiveness has been proved by some extensive meta-studies (e.g. Hoque, 2014; Cooper et al., 2017) even in non-profitable environments (Zhijun, 2014).

Some gaps on the BSC theory and certain limitations on the use of the BSC approach have been also raised by some scholars including Kaplan himself (Noerreklit, 2000; Kaplan, 2009; Hoque, 2014). The main group of limitations and gaps can be summarized by the lack of clear scientific methods to design the structure of the BSC and the selection of the KPIs which have to compose it.

Those gaps have been tried to be fulfilled by research studies in the use of systemic and analytical methods such as Analytical Hierarchical Process (AHP) (Göleç, 2015; Kang et al., 2016), fuzzy logic (chytas et al., 2011; Rabbani et al., 2014), Analytical Network Process (ANP) (Boj et al., 2014; Dincer et al., 2016). These methods have in common the central idea of selecting main KPIs based on weights that have been established from surveys and qualitative data, but not on actual and experimental data.

The use of statistical tools such as multivariate techniques and multiple regression to assess the impact of each KPI on organization performance and as a multi-criteria decision method have been suggested by Rodriguez-Rodriguez $\mathrm{R}$ et al. $(2009,2014)$ and confirmed as a valid method (SanchezMarquez R et al., under review, Morard et al., 2013) in manufacturing environment when using actual data. Nevertheless, methods developed on those works are not always clearly distinguishing between actionable KPIs and output KPIs, which is critical on the application of Regression Methods such as Partial Least Squares (PLS). Moreover, the complexity of the BSC is not sufficiently tackled in those methods, which is also mentioned by Hoque (2014) as one of the main issues on the use of BSC as a PMS. Therefore, a method which first select main system output KPIs (which also derives in a complexity reduction of the BSC) and then test the effectiveness of specific strategies through input (actionable) KPIs is needed and not sufficiently developed yet. By the way, the use of KPIs with statistical multivariate methods is based on the use of time series, and many papers on time series method are making clear that prior to the use of time series, autocorrelation effects have to be checked and addressed to "whitened" the data and make the time series stationary (Dickey and Fuller, 1979; Wu et al., 1989; Becketti, 2013). This important issue is not even mentioned on any of the research works available and has to be included as part of the methods which deal with KPIs actual data and thus, time series.

Many research works are made on the importance of IC and IA for the success and the objectives accomplishment within the organizations (Nahapiel \& Goshal, 1998; Stewart
\& Ruckdeschel, 1998; Delios \& Beamish, 2001; Kaufmann \& Schneider, 2004; Chang et al. 2008; Dumay, 2014) and the need of establishing methods to measure it and its efficiency in the organization performance (Teece, 2000; Jurczak, 2008; Boj et al., 2014), but none of them are using actual KPIs data to develop those methods.

Competency is one of the main factors affecting IC through the already stated relationship between them, since a competency can be defined as "a set of observable behaviors acquired through knowledge, skills and experiences that contribute to successful work accomplishments" (Johstone \& Soares, 2014) and IC as "knowledge, talents and skills suitable to be used to create wealth" (Stewart \& Ruckdeschel, 1998). It becomes obvious that measuring competency of people is critical for the organizations. By the way, most of the works on the development of competency-based educational programs (Brodersen et al., 2017; Johnstone \& Soares, 2014; Mirabile, 1997; Morcke et al., 2013; Norman et al., 2014; Pijl-Zieber et al., 2014; Sturgis et al., 2011; Ten Cate, 2013) are based on the concept of assessing competency level by a specific outcome which has to be clearly defined in advance for both the assessed person and the evaluators. Therefore, a clear outcome has to be included in the method to confirm the effectiveness of L\&DPs based on competency.

Dumay (2014) in an extensive work on the literature about IC showed different ways to measure it within the organizations and other scholars afterwards (Boj et al. 2014, Varmazyar et al. 2016) proved using analytical methods how IC can impact the whole performance of organizations by using KPIs in a BSC framework. Nevertheless, empirical data is used indirectly to confirm the conclusions but is not used directly in the method to discover the systemic mathematical model, so a more robust method is necessary to prove/disprove the impact of IC in general and L\&DPs in particular.

In the next section, the proposed methodology will be based on the assessment of the effectiveness of L\&DPs with real improvement actions as a clear competency output. The hypothesized improvement of manufacturing processes will be tested through the impact into BSC KPIs of those actions implemented by people enrolled in the programs.

\section{Proposed Methodology}

The proposed methodology has been tested to prove its effectiveness and validity by means of a case study approach using a real company's Balanced Scorecard actual data from three consecutive years in a structure of monthly KPIs. The company is a leading multinational car manufacturer company from the automotive sector in Spain. Both the training programs and the L\&DPs which use competency-based approach directly affect almost 8000 employees of the car manufacturer and indirectly up to 20.000 employees of its suppliers' companies which have also to enroll their em- 
ployees in L\&DPs as an important aspect of the commercial agreements between companies. The main company, the car manufacturer alone, spends about 60.000 h. a year of individual training, and the competency-based program studied in detail in this paper is composed of $6400 \mathrm{~h}$. on individual training and a similar figure of shop-floor coaching to complete the process improvement projects which are the output that serves as the main competency achievement criteria. It became obvious that with these numbers, a scientific study that proves effectiveness of these programs is more than necessary. Although some rough estimations on the benefits of those programs are made to select and close the projects, which show a yearly cost saving of several millions US dollars, only in the Spanish facilities, assumptions made on savings estimations suggest that a more empirical method which relates those process improvement actions with the official product cost is needed to prove its actual effectiveness. By the way, as the BSC theory indicates, company effectiveness is not only measured through financial metrics, but also by means of the use of other non-financial ones, therefore the use of statistical Multivariate techniques will be the main tool within the methodology to assess the impact of those L\&DPs on the BSC main KPIs as a measure of systemic effectiveness.

Multivariate analysis of training when we consider it, as an overall resource does not give a conclusive result if we only use training courses as training hours. Therefore, we cannot see a significant impact of training hours of the whole company on KPIs, even considering lagged effects by using lagged time series.

This partial result can be explained by the fact that no specific outcomes and dates are set up for all training initiatives. Therefore, it is not possible to correlate these training events with KPIs on a certain date.

By the way, it is not happening the same thing when we consider a specific Learning \& Development Program with specific actions (outcomes) well defined in time and when those initiatives are selected and aligned with the strategy of the company through the Scorecard's KPIs.

Let us take as System output the selection of essential KPIs of the Company and as input, the actions derived from 6 Sigma projects. Six Sigma program has, as a competency requirement, the execution of process improvement projects. Therefore, it is possible to track improvements made on a specific date.

It is also necessary to transform time series of both types of actions from Six Sigma projects, Interim Corrective/Containment Actions (ICAs) and Permanent Corrective Actions (PCAs), using lagged time series technique, as first proposed by Sanchez-Marquez et al. (under review) it is essential to see relationships between variables that have a lagged effect on the system.
We also need to transform all KPIs such as TTP-B, L\&OH $\mathrm{CPU}$, etc., into incremental variables to see relationship between actions and the change in the metrics. Therefore, instead of $\mathrm{L} \& \mathrm{OH} \mathrm{CPU}$, we need to have $\triangle \mathrm{L} \& \mathrm{OH} \mathrm{CPU}$ and the same transformation for the rest of the selected KPIs of the Scorecard. We apply this transformation after autocorrelation effect assessment to account for its effects on the result as well. The resulting time series do not present any autocorrelation effect (Box GE et al., 2008). We have assessed autocorrelation using Time Series Plot, Autocorrelation Function (ACF) and Partial Autocorrelation Function (PACF) (Wu JP and Wei S, 1989; Box GE et al., 2008; http://www.minitab.com) complemented with the Augmented Dickey-Fuller t-test for Stationary time series (Dickey and Fuller, 1979; Wu JP and Wei S, 1989; Becketti, 2013). To select the most important KPIs and simplify the BSC we can apply one of the methods proposed by Rodriguez-Rodriguez et al. (2009), Morard et al. (2013) or Sanchez-Marquez et al. (under review), where we have previously treated the time series for autocorrelation as a first step, as indicated for the present method.

Therefore, our proposed method consists of:

1. Assess Autocorrelation for time series and transform them as needed

2. Simplify BSC structure and select the most important KPIs (Sanchez-Marquez et al., under review; Rodriguez-Rodriguez et al., 2009; Morard et al., 2013)

3. Apply multivariate statistics methods such as Partial Least Squares (PLS) using as output variables the main KPIs of the Balanced Scorecard of the Organization (use the transformed version of time series as appropriate)

4. Use PCA and ICA and their transformed lagged time series as input variables for PLS

5. Apply PLS and/or Multiple Regression to find the best empirical model

6. Find the optimum of the empirical model

7. Translate the results into practical conclusions for managers and executives

\section{Results and discussion}

The clearest, interesting and strong relationships are the ones, which appear using multivariate technique PLS between cost per unit and the actions of Six Sigma Program. Thus, it is possible to establish a clear relationship between such actions and the increment on CPU in terms of \$/unit as shown on table 1: 
Table 1 PLS model coefficients.

\begin{tabular}{|c|c|c|c|c|c|}
\hline & \begin{tabular}{|l} 
ON-LINE \\
(delta)
\end{tabular} & $\begin{array}{l}\text { PTS } \\
(\text { delta })\end{array}$ & $\begin{array}{l}\begin{array}{l}\text { L\&OH CPU } \\
\text { (delta) }\end{array} \\
\end{array}$ & $\begin{array}{l}\text { ABS } \\
\text { (delta) }\end{array}$ & $\begin{array}{l}\text { TTP-B } \\
\text { (delta) }\end{array}$ \\
\hline Constant & 29,6663 & $-0,0140568$ & 39,1816 & $\odot, 0012867$ & $-0,0240075$ \\
\hline ICAs & $-0,7097$ & $\odot, 0 \odot \odot \odot 948$ & $-0,3524$ & $-\odot, 000 \odot \odot 44$ & $\odot, 0 \odot \odot 2755$ \\
\hline ICAs $t-1$ & $-1,3431$ & $\odot, 0001795$ & $-0,6669$ & $-0,0000083$ & 0,0005214 \\
\hline PCAS & $-7,2365$ & 0,0009671 & $-3,5935$ & $-\odot, 0 \odot \odot \odot 45$ & $\odot, 0028094$ \\
\hline PCAs $t-1$ & \begin{tabular}{|l|}
$-17,7993$ \\
\end{tabular} & $\odot, 0 \odot 23786$ & $-8,8387$ & $-0,0001106$ & 0, 0069101 \\
\hline
\end{tabular}

As it can be seen in table 1, coefficients are negative, it means it is produced a saving on Cost per Unit from each improvement action. This data is statistically significant, as confirmed by p-value of the ANOVA (Analysis of Variance) regression model shown on table 2 :

Table 2 ANOVA model for $\mathrm{L} \& \mathrm{OH}$ CPU (delta)

\begin{tabular}{|l|l|l|l|l|l|}
\hline Source & DF & SS & MS & F & P \\
\hline Regression & 1 & 18492,6 & 18492,6 & 8,68 & 0,008 \\
\hline $\begin{array}{l}\text { Residual } \\
\text { Error }\end{array}$ & 21 & 44734,4 & 2130,2 & & \\
\hline Total & 22 & 63227 & & & \\
\hline
\end{tabular}

Using standardized inputs variables and the "Stepwise" heuristic method in Minitab, which uses p-value and R2 predictive to reduce the model, we obtain the following result model that has a high quality in terms of statistical significance and stability according to a high R-sqr predictive of 85\% (table 5) and a VIF < 5 for all terms included in model (table 6). Therefore, we can conclude the following is a good model to predict cost per unit:

Regression Analysis: L\&OH CPU (delta) versus ICAs; ICAs t-1; PCAs; PCAs t-1:

Method: Continuous predictor standardization

Table 3 Levels coded to -1 and +1

\begin{tabular}{|l|l|l|}
\hline Predictor & Low & High \\
\hline ICAs & 0 & 5 \\
\hline ICAs t $-\mathbf{1}$ & 0 & 6 \\
\hline PCAs & $\odot$ & 12 \\
\hline PCAs t $-\mathbf{1}$ & 0 & 12 \\
\hline
\end{tabular}

Method: Stepwise Selection of Terms where we select $\alpha$ to enter $=0,05 ; \alpha$ to remove $=0,05$
Stepwise procedure added terms during the procedure to maintain a hierarchical model at each step. 
Table 4 ANOVA model for L\&OH CPU (delta) using stepwise method

Table 5 Model Summary for L\&OH CPU (delta)

Table 6 Coded Coefficients for $\mathrm{L} \& \mathrm{OH}$ CPU (delta) using stepwise method

\begin{tabular}{|l|l|l|l|l|l|}
\hline Source & DF & Adj SS & Adj MS & F-Value & P-Value \\
\hline Regression & 8 & 61417 & 7677,1 & 59,38 & $\odot$ \\
\hline ICAs & 1 & 46,8 & 46,8 & $\odot, 36$ & $\odot, 557$ \\
\hline ICAs t-1 & 1 & 113,8 & 113,8 & $\odot, 88$ & $\odot, 364$ \\
\hline PCAs & 1 & 3674,5 & 3674,5 & 28,42 & $\odot$ \\
\hline PCAs t-1 & 1 & 5136,5 & 5136,5 & 39,73 & $\odot$ \\
\hline ICAs t-1*ICAs t-1 & 1 & 3621,6 & 3621,6 & 28,01 & $\odot$ \\
\hline PCAs t-1*PCAs t-1 & 1 & 21636,6 & 21636,6 & 167,36 & $\odot$ \\
\hline ICAs*PCAs & 1 & 798,6 & 798,6 & 6,18 & $\odot, \odot 26$ \\
\hline PCAs* PCAS t -1 & 1 & 2877,4 & 2877,4 & 22,26 & $\odot$ \\
\hline Error & 14 & 1809,9 & 129,3 & & \\
\hline Lack- of -Fit & 13 & 1797,4 & 138,3 & 11,06 & $\odot, 232$ \\
\hline Pure Error & 1 & 12,5 & 12,5 & & \\
\hline Total & 22 & 63227 & & & \\
\hline
\end{tabular}

\begin{tabular}{|l|l|l|l|}
\hline S & R-sq & R-sq(adj) & R-sq(pred) \\
\hline 11,3702 & $97,14 \%$ & $95,50 \%$ & $85,85 \%$ \\
\hline
\end{tabular}

\begin{tabular}{|l|l|l|l|l|l|}
\hline Term & Coef & SE Coef & T-Value & P-Value & VIF \\
\hline Constant & $-12,33$ & 5,02 & $-2,46$ & $\odot, 028$ & \\
\hline ICAs & $-4,15$ & 6,89 & $-\odot, 6$ & $\odot, 557$ & 3,84 \\
\hline ICAs t-1 & 5,23 & 5,57 & $\odot, 94$ & $\odot, 364$ & $2, \odot 7$ \\
\hline PCAs & 39,18 & 7,35 & 5,33 & $\odot$ & 1,78 \\
\hline PCAs t-1 & $-63,6$ & 10,1 & $-6,3$ & $\odot$ & 3,36 \\
\hline ICAs t-1*ICAs t-1 & 42,53 & $8, \odot 4$ & 5,29 & $\odot$ & 1,66 \\
\hline PCAs t-1*PCAs t-1 & $-106,55$ & 8,24 & $-12,94$ & $\odot$ & 1,21 \\
\hline ICAs PCAs & $-32,3$ & 13 & $-2,49$ & $\odot, \odot 26$ & 4,51 \\
\hline PCAs * PCAs t-1 & 88,1 & 18,7 & 4,72 & $\odot$ & 4,57 \\
\hline
\end{tabular}

Therefore, the model for manufacturing cost can be built from de coefficients shown on table 6 and it is characterized by the equation (1):

$\triangle \mathrm{L} \& 0 H \mathrm{CPU}=2,82+1,27$ ICAs-26,61 (ICAs) $)_{\mathrm{t}-1}-2,77$

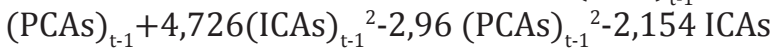
PCAs+2,448 PCAs (PCAs)
The model for Body Lines efficiency $(\Delta T T P-B)$ has a moderate predictive power as denoted by a R2 (pred) of about 38\% (table 9):

Regression Analysis: TTP-B (delta) versus ICAs; ICAs t-1; PCAs; PCAs t-1

Method: Continuous predictor standardization 
Table 7 Levels coded to -1 and +1

\begin{tabular}{|l|l|l|}
\hline Predictor & Low & High \\
\hline ICAs & $\odot$ & 5 \\
\hline ICAs t -1 & $\odot$ & 6 \\
\hline PCAs & $\odot$ & 12 \\
\hline PCAs t -1 & $\odot$ & 12 \\
\hline
\end{tabular}

Using Stepwise Method for the selection of Terms with $\alpha$ to enter $=0,05 ; \alpha$ to remove $=0,05$, we arrive to the following model:

Table 8 Analysis of Variance for TTP-B (delta) using stepwise

\begin{tabular}{|l|l|l|l|l|l|}
\hline Source & DF & Adj SS & Adj MS & F-Value & P-Value \\
\hline Regression & 2 & $\odot, \odot 18992$ & $\odot, \odot \odot 9496$ & 18,8 & $\odot$ \\
\hline PCAs & 1 & $\odot, \odot 178$ & $\odot, \odot 178$ & 35,24 & $\odot$ \\
\hline PCAs ${ }^{*}$ PCAS & 1 & $\odot, \odot \odot 4658$ & $\odot, \odot \odot 4658$ & 9,22 & $\odot, \odot \odot 7$ \\
\hline Error & $2 \odot$ & $\odot, \odot 101 \odot 4$ & $\odot, \odot \odot \odot 5 \odot 5$ & & \\
\hline Lack- of -Fit & 19 & $\odot, \odot 1 \odot \odot 99$ & $\odot, \odot \odot \odot 532$ & 118,12 & $\odot, \odot 72$ \\
\hline Pure Error & 1 & $\odot, \odot \odot \odot \odot \odot 5$ & $\odot, \odot \odot \odot \odot \odot 5$ & & \\
\hline Total & 22 & $\odot, \odot 29 \odot 96$ & & & \\
\hline
\end{tabular}

Table 9 Summary for TTP-B (delta)

\begin{tabular}{|l|l|l|l|}
\hline S & R-sq & R-sq(adj ) & R-sq(pred) \\
\hline$\odot, 022476$ & $65,27 \%$ & $61,80 \%$ & $37,74 \%$ \\
\hline
\end{tabular}

Table 10 Coded Coefficients for TTP-B (delta)

\begin{tabular}{|l|l|l|l|l|l|}
\hline Term & Coef SE & Coef & T-Value & P-Value & VIF \\
\hline Constant & $\odot, 02358$ & $\odot, 0 \odot 759$ & 3,11 & $\odot, 0 \odot 6$ & \\
\hline PCAs & 0,067 & $\odot, 0113$ & 5,94 & $\odot$ & 1,07 \\
\hline PCAs*PCAs & 0,0465 & 0,0153 & 3,04 & $\odot, 0 \odot 7$ & 1,07 \\
\hline
\end{tabular}

Regression Equation (2) in Uncoded Units can be built using the coefficients from table 10 :

$$
\Delta(\text { TTP-B })=0,0032-0,00435 \text { PCAs }+0,001293 \text { PCAs }^{2}(2)
$$

Independence of residuals and equal variance assumptions have been checked for the validity of the models. Addition- ally, the lack of partial correlation effect has been proved as well on predictors time series to avoid overestimation of regression coefficients.

Using the optimizing tool from Minitab, we have the following sensitivity analysis of variables for the KPI called $\triangle \mathrm{L} \& \mathrm{OH}$ CPU: 
Figure 2 Minitab optimization tool. Model: L\&OH CPU vs ICA, ICA t-1, PCA and PCA t-1

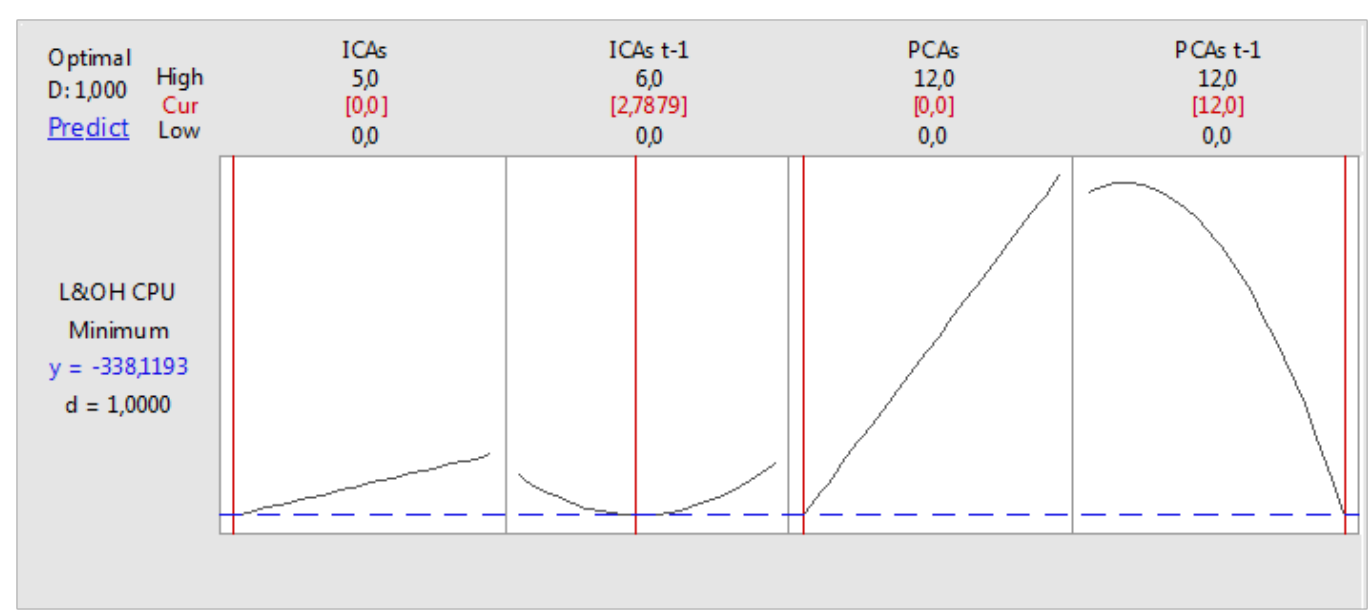

shows us that once we have considered a point, for ICA it would be a local minimum, (6), and for PCA it would be a local maximum, (7). It means, for a certain value of PCA, there is an inflexion point for ICA, which is a minimum, because the quadratic term of the number of ICAs has a coefficient that is positive and the other way around for the number of PCAs.

In order to solve this problem and obtain the optimum for $\triangle \mathrm{L} \& \mathrm{OH}$ CPU we can use Excel solver that offers three families of mathematical algorithms: "GRG nonlinear”, "LP simplex" for linear problems and the "Evolutionary" algorithm. For our analysis of the simplified equation (3) we will use the "Evolutionary" as there is not a finite number of maximums and minimums and the result of "GRG nonlinear" normally depends on the start point of the algorithm and we do not have a linear problem to use "LP simplex". Additionally, we can argue that evolutionary algorithms are useful to find solutions when there is not a unique optimum as it tries to explore the complete inferential space.

On Figure 3, we graphically illustrate the nature of the problem of finding the optimum using the model of equation (3). This 3-D graph was built by generating all possible combinations of integer numbers for ICA and PCA from 0 to 6 and 0 to 12 respectively which gives us 91 different treatment combinations. Monte Carlo simulation of cost ( $\triangle \mathrm{L} \& \mathrm{OH} \mathrm{CPU})$ within the inferential space of ICA and PCA can be used as well to generate the graph, mainly when variables are continuous instead of integer. Now, it becomes even more obvious that the problem does not have neither only one maximum nor one minimum. 
Figure 3 Surface Plot of $\triangle \mathrm{L} \& \mathrm{OH} \mathrm{CPU}$ versus PCA and ICA

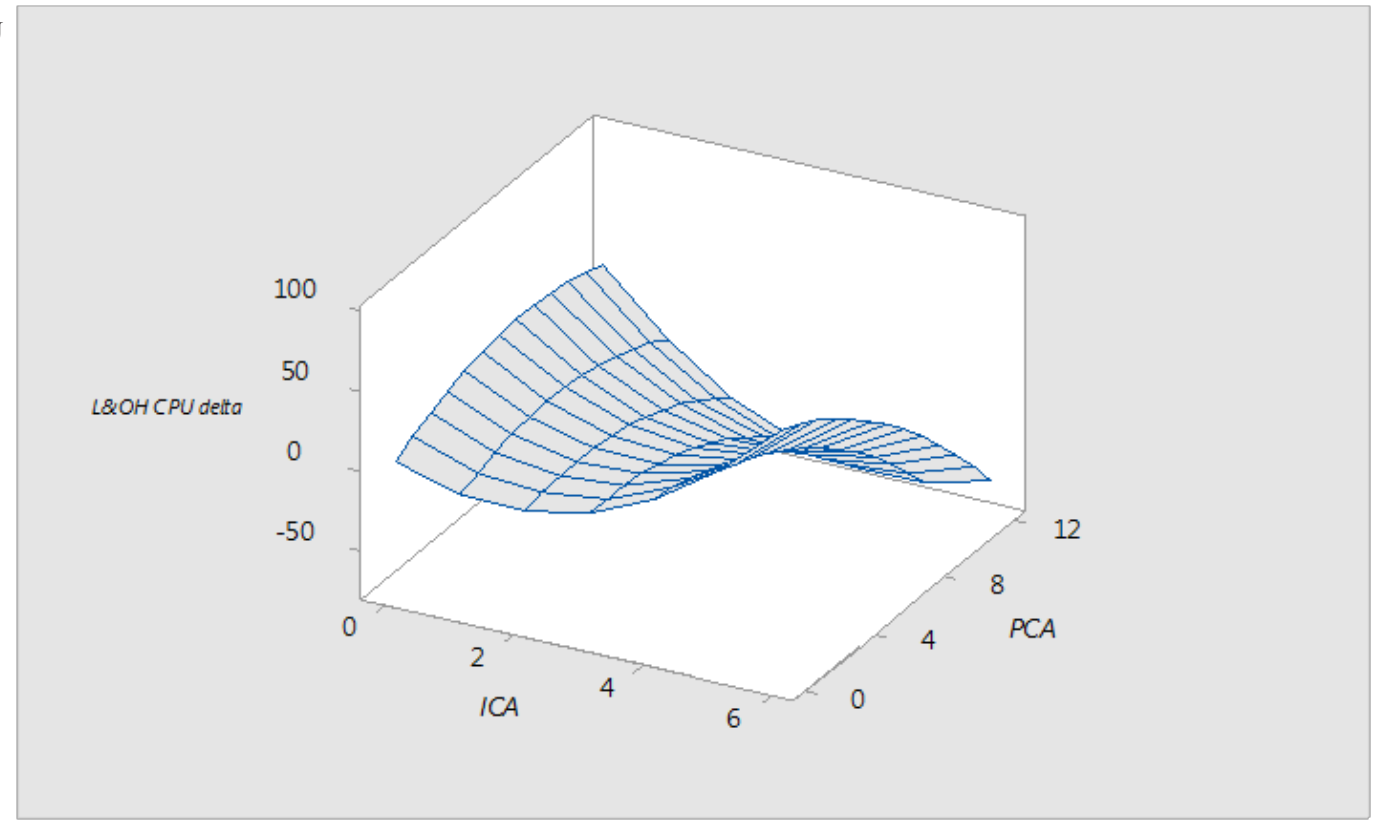

The main limitation of this type of algorithms is the need of establishing limits for variables. Otherwise, the algorithm may not converge into a solution. We established the minimum and maximum for ICA and PCA inside the same inferential space as for obtaining the model to ensure the validity of the model itself, as it is an empirical model. Therefore:

$$
\begin{array}{ll}
- & \mathrm{ICA}=[0,6] \\
- & \mathrm{PCA}=[0,12]
\end{array}
$$

Final result, after several iterations (iterations using Excel solver tool included within the appendix) seems to tell us that this was the best algorithm as predicted, as the linear one cannot be applied because it is not a linear problem and when we used "GRG nonlinear" it gave us different results depending on the point we started the algorithm. The optimum seems to be in the maximum capacity to execute and implement PCAs and for the case of 12 PCAs; the optimum is set at 4 ICAs. We can establish a practical rule to establish the number of ICAs as a function of PCAs. Therefore, ICA would be approximately $1 / 3$ of PCA.

A possible explanation for the fact that ICA and PCA are related through an interaction, at least when analyzing $\triangle \mathrm{CPU}$, may be that ICA and PCA are interrelated through the number of projects carried out each month. Therefore, the optimum number of ICAs would be the minimum needed depending on the issues that requires a containment action. Then, for 12 PCAs, we need to implement 4 ICAs, not more, not less. The practical interpretation is that ICAs are costing money, so it is not optimum from the Cost perspective to implement ICAs for all projects, otherwise the relationship would be another one as the typical rate between PCAs and ICAs is not 3 , but 1.66 , since for the period studied $\sum$ PCAs $/ \sum$ ICAs $=1.66$.
Quadratic term of PCAs could be related to variety rather than to quantity. It means that if we look at the actions implemented during the months with more quantity, then there appears to be more heterogeneity in the areas where the actions were implemented, so it is boosting their effectiveness through synergies between different areas. On the other hand, quadratic term of ICAs is telling us that they are costing money unless we set the number to the minimum possible according to interaction term and equation (3), therefore depending on the number of PCAs.

This is the analysis for the impact of Six Sigma Program to the manufacturing cost per unit. Another similar study using KPIs could be done to establish the impact on warranty cost saving as it is not considered as a manufacturing cost in all cases, so for us it is out of the scope of the present paper.

As for the optimization of the function that determines the efficiency of manufacturing lines, measured by variable TTP-B, we have:

$\triangle T T P-B=0.0032-0.00435 P C A+0.001293 P C A^{2}$

In addition, to work out the optimum, that is the maximum of the function:

$$
\begin{aligned}
& \frac{d(\triangle T T P-B)}{d P C A}=-0.00435+0.001293 P C A=0 \\
& P C A=0.00435 / 0.001293=3.36 \\
& \frac{d^{2}(\Delta T T P-B)}{d P C A^{2}}=0.001293>0 \rightarrow \text { Minimum }
\end{aligned}
$$


Therefore, for $\triangle \mathrm{TTP}-\mathrm{B}$, we need to have the number of PCAs to the maximum of the capacity of execution, as for CPU to be minimized we had to do the same. This indicates that there is no conflict between these two main KPIs.

\section{Conclusions and future research works}

- We can confirm the relationships between variables and the main conclusions from the systemic method used by Rodriguez-Rodriguez et al. (2009), Morard et al. (2013) and Sanchez-Marquez et al. (under review), giving validity to both methods and studies, the present one and the ones previously mentioned.

- $\quad$ It is possible to use the present method to establish relationships between L\&DPs and company's performance metrics when programs include actions and outcomes on a specific date.

- $\quad$ Both multivariate analysis and multiple regression show us an impact of the technical programs, on cost per unit and internal processes, which confirm a positive impact on a metric of Learning and Growth perspective in short term and long term as predicted by Balanced Scorecard's theory (Kaplan \& Norton, 1992).

- $\quad$ Specific L\&DPs with the suitable learning and development environment to apply new knowledge acquired during training courses has been proved to be an important Intangible Asset. All these concepts together can be understood as the acquisition of new competence in the context of IC.

- $\quad$ This method could be used in future research works to assess the impact of L\&DPs on metrics outside manufacturing environment to confirm its validity and generalize the method.

- $\quad$ Future studies may be focused on the design of specific assessment procedures within the companies for the effectiveness of L\&DPs taking the whole advantage of the presented method.

- $\quad$ It has also been confirmed the effectiveness of Six Sigma programs in manufacturing environment when well defined and business aligned process improvement projects are part of the program. As Six Sigma programs are a very common worldwide, the confirmation of their effectiveness is an important finding by itself.

- $\quad$ The use of transformed time series into lagged ones has been confirmed as a key technique when dealing with KPIs.
- $\quad$ The use of transformed time series into incremental ones has also been revealed as a Key technique to see relationships between KPIs, as an original contribution of this research work to detect impacts on the system which otherwise would be not detected.

- $\quad$ As no conclusive results were found on specific training courses, future research works can be done to assess the impact of those ones rather than L\&DPs, which have a continuity in time. Some concepts, tools and techniques from the present work can be used for that purpose as well.

- A very likely interpretation is that training has no impact by itself and therefore "training programs" have to be transformed into "competency programs" with specific and real outcomes to assess their effectiveness in the system and thus in the Intellectual Capital of the organization as Six Sigma Program has proved to be in this research.

\section{Index of Acronyms and Abbreviations}

- $\quad$ AHP: Analytical Hierarchical Procedure

- $\quad$ ANP: Analytical Network Procedure

- $\quad$ BSC: Balanced Scorecard

- $\quad$ IA: Intangible Assets

- $\quad$ IC: Intellectual Capital

- $\quad$ KPIs: Key Performance Indicators

- $\quad$ L\&DPs: Learning and Development Programs

- MVA: Multivariate

- $\quad$ PLS: Partial Least Squares

- $\quad$ PMS: Performance Management System

\section{Appendix - optimization using Excel solver tool}

Iteration 1, using Excel Solver "Evolutionary” algorithm with predictors constraints set at ICA $<100$ and PCA $<100$, where we can see the optimum is found at ICA $=24,41176$ and PCA at the maximum of its value, which is PCA $=100$. The result is then adjusted to their best near integer values of 25 and 100 and confirmed by additional combinations of values. Everything on table 11. 
Table 11 Iteration 1

\begin{tabular}{|c|c|c|}
\hline ICAs & PCAs & L\&OH CPU (delta) \\
\hline $\mathbf{2 4 , 4 1 1 7 6}$ & $\mathbf{1 0 0}$ & $\mathbf{- 7 1 8 7 , 5 6 5 2 9 4}$ \\
\hline $\mathbf{2 5}$ & $\mathbf{1 0 0}$ & $\mathbf{- 7 1 8 5 , 9 3}$ \\
\hline 25 & 100 & $-7185,93$ \\
\hline 25 & 100 & $-7185,93$ \\
\hline 30 & 100 & $-7039,98$ \\
\hline 20 & 100 & $-7095,58$ \\
\hline 20 & 100 & $-7095,58$ \\
\hline 35 & 100 & $-6657,73$ \\
\hline 15 & 100 & $-6768,93$ \\
\hline 0 & 100 & $-4371,18$ \\
\hline 1 & 100 & $-4597,194$ \\
\hline 2 & 100 & $-4813,756$ \\
\hline 3 & 100 & $-5020,866$ \\
\hline
\end{tabular}

Iteration 2, using Excel solver "Evolutionary" algorithm with predictor constraints set at ICA $<20$ and PCA $<20$, where we can see the optimum is found at ICA $=6,180702$ and PCA at the maximum of its value, which is PCA $=20$.
The result is then adjusted to their best near integer values of 6 and 20 and confirmed by additional combinations of values. See table 12.

Table 12 Iteration 2

\begin{tabular}{|c|c|c|}
\hline ICAs & PCAs & L\&OH CPU (delta) \\
\hline $\mathbf{6 , 1 8 0 7 0 2}$ & $\mathbf{2 0}$ & $-\mathbf{2 3 3 , 3 1 8 3 1 9 9}$ \\
\hline $\mathbf{6}$ & $\mathbf{2 0}$ & $-\mathbf{2 3 3 , 1 6 4}$ \\
\hline 7 & 20 & $-230,146$ \\
\hline 8 & 20 & $-217,676$ \\
\hline 5 & 20 & $-226,73$ \\
\hline 4 & 20 & $-210,844$ \\
\hline 3 & 20 & $-185,506$ \\
\hline 2 & 20 & $-150,716$ \\
\hline 1 & 20 & $-106,474$ \\
\hline 0 & 20 & $-52,78$ \\
\hline
\end{tabular}

Iteration 3, using Excel solver "GRG nonlinear" algorithm with predictor constraints set at ICA $<30$ and PCA $<30$, and start point at the optimum of iteration $2(6,20)$, where we can see the optimum is found at ICA $=8,459585$ and PCA again at the maximum of its value, which is PCA $=30$. The result is then adjusted to their best near integer values of 8 and 30 and confirmed by additional combinations of values. See table 13 .

\begin{tabular}{|c|c|c|}
\hline ICAs & PCAs & L\&OH CPU (delta) \\
\hline $\mathbf{8 , 4 5 9 5 8 5}$ & $\mathbf{3 0}$ & $\mathbf{- 5 7 2 , 3 9 4 2 1 9 2}$ \\
\hline $\mathbf{8}$ & $\mathbf{3 0}$ & $\mathbf{- 5 7 1 , 3 9 6}$ \\
\hline 9 & 30 & $-571,014$ \\
\hline 7 & 30 & $-562,326$ \\
\hline 10 & 30 & $-561,18$ \\
\hline 6 & 30 & $-543,804$ \\
\hline 11 & 30 & $-541,894$ \\
\hline 5 & 30 & $-515,83$ \\
\hline 12 & 30 & $-513,156$ \\
\hline 4 & 30 & $-478,404$ \\
\hline 13 & 30 & $-474,966$ \\
\hline 2 & 30 & $-375,196$ \\
\hline 3 & 30 & $-431,526$ \\
\hline
\end{tabular}


Iteration 4, using Excel solver "Evolutionary" algorithm with predictor constraints set at ICA $<30$ and PCA $<30$, where we can see the optimum is found at ICA $=8,459585$ and PCA again at the maximum of its value, which is PCA $=30$. This result confirms the optimum found at iteration
3 , with the advantage of not needing to setup a start point for predictors. The result is then adjusted to their best near integer values of 8 and 30 and confirmed by additional combinations of values. See table 14 .

Table 14 Iteration 4

\begin{tabular}{|l|c|c|}
\hline ICAs & PCAs & L\&OH CPU (delta) \\
\hline $\mathbf{8 , 4 5 9 5 8 5}$ & $\mathbf{3 0}$ & $\mathbf{- 5 7 2 , 3 9 4 2 1 9 2}$ \\
\hline $\mathbf{8}$ & $\mathbf{3 0}$ & $\mathbf{- 5 7 1 , 3 9 6}$ \\
\hline 9 & 30 & $-571,014$ \\
\hline 7 & 30 & $-562,326$ \\
\hline 10 & 30 & $-561,18$ \\
\hline 6 & 30 & $-543,804$ \\
\hline 11 & 30 & $-541,894$ \\
\hline 5 & 30 & $-515,83$ \\
\hline 12 & 30 & $-513,156$ \\
\hline 4 & 30 & $-478,404$ \\
\hline 13 & 30 & $-474,966$ \\
\hline 2 & 30 & $-375,196$ \\
\hline 3 & 30 & $-431,526$ \\
\hline
\end{tabular}

Iteration 5, using Excel solver "Evolutionary" algorithm with predictor constraints set at ICA $<12$ and PCA $<12$, where we can see the optimum is found at ICA $=4,357596$ and PCA once again at the maximum of its value, which is $\mathrm{PCA}=12$. This result confirms the optimum is found at the maximum value of PCA and ICA depends on PCA as expected. The result is then adjusted to their best near integer values of 4 and 12 and confirmed by additional combinations of values. See table 15 .

Table 15 Iteration 5

\begin{tabular}{|c|c|c|}
\hline ICAs & PCAs & L\&OH CPU (delta) \\
\hline $\mathbf{4 , 3 5 7 5 9 6}$ & $\mathbf{1 2}$ & $\mathbf{- 7 1 , 1 2 8 3 3 7 7 1}$ \\
\hline $\mathbf{4}$ & $\mathbf{1 2}$ & $\mathbf{- 7 0 , 5 2 4}$ \\
\hline 5 & 12 & $-69,178$ \\
\hline 8 & 12 & $-8,428$ \\
\hline 5 & 12 & $-69,178$ \\
\hline 4 & 12 & $-70,524$ \\
\hline 3 & 12 & $-62,418$ \\
\hline 2 & 12 & $-44,86$ \\
\hline 1 & 12 & $-17,85$ \\
\hline 0 & 12 & 18,612 \\
\hline
\end{tabular}

Iteration 6, using Excel solver "Evolutionary" algorithm with predictor constraints set at ICA $<20$ and PCA $=0$, where we can see the optimum is found at ICA $=1,622937$ and PCA $=0$. This result is worst in terms of $\mathrm{L} \& \mathrm{OH} \mathrm{CPU}$ delta than the one achieved in iteration 5. The result is then adjusted to their best near integer values of 2 and 0 and confirmed by additional combinations of values. See table 16 .

\begin{tabular}{|c|c|c|}
\hline ICAs & PCAs & L\&OH CPU (delta) \\
\hline $\mathbf{1 , 6 2 2 9 3 7}$ & $\mathbf{0}$ & $\mathbf{- 9 , 6 2 7 9 2 6 3 6 5}$ \\
\hline $\mathbf{2}$ & $\mathbf{0}$ & $\mathbf{- 8 , 9 5 6}$ \\
\hline 3 & 0 & $-0,666$ \\
\hline 4 & 0 & 17,076 \\
\hline
\end{tabular}


Iteration 7, using Excel solver "GRG nonlinear" algorithm with predictor constraints set at ICA $>0$ and PCA $>0$. The result is not converging to a possible value of predictors,

Table 17 Iteration 7

\begin{tabular}{|l|l|c|}
\hline ICAs & PCAs & L\&OH CPU (delta) \\
\hline $1,12 \mathrm{E}+08$ & $6,76 \mathrm{E}+08$ & $-3,37508 \mathrm{E}+17$ \\
\hline
\end{tabular}

Iteration 8, using Excel solver "GRG nonlinear" algorithm with predictor constraints set at ICA $<20$ and PCA = 0 , where we can see the optimum is found at ICA $=1,622937$ and $\mathrm{PCA}=0$. This result is confirming the one from iteration as their constraints are not actual constraints $(>0)$. See Table 17.

Table 18 Iteration 8

\begin{tabular}{|c|c|c|}
\hline ICAs & PCAs & L\&OH CPU (delta) \\
\hline $\mathbf{1 , 6 2 2 9 3 7}$ & $\mathbf{0}$ & $\mathbf{- 9 , 6 2 7 9 2 6 3 6 5}$ \\
\hline $\mathbf{2}$ & $\mathbf{0}$ & $\mathbf{- 8 , 9 5 6}$ \\
\hline 3 & 0 & $-0,666$ \\
\hline 4 & 0 & 17,076 \\
\hline
\end{tabular}

Iteration 9. Simulation without Solver, using the equation (3) for all positive integer values of PCA between 0 and 12, which is the maximum capacity and the inference space. It

Table 19 Iteration 9(see also table 20)
6. The result is then adjusted to their best near integer values of 2 and 0 and confirmed by additional combinations of values. See table 18. confirms the optimum from iteration 5 using the actual inferential space. See tables 19 and 20.

\begin{tabular}{|c|c|c|}
\hline ICAs & PCAs & L\&OH CPU (delta) \\
\hline 0 & 0 & 2,82 \\
\hline 1 & 0 & $-7,794$ \\
\hline 2 & 0 & $-8,956$ \\
\hline 3 & 0 & $-0,666$ \\
\hline 0 & 1 & 9,768 \\
\hline 1 & 1 & -3 \\
\hline 2 & 1 & $-6,316$ \\
\hline 3 & 1 & $-0,18$ \\
\hline 0 & 2 & 15,692 \\
\hline 1 & 2 & 0,77 \\
\hline 2 & 2 & $-4,7$ \\
\hline 3 & 2 & $-0,718$ \\
\hline 0 & 3 & 20,592 \\
\hline 1 & 3 & 3,516 \\
\hline 2 & 3 & $-4,108$ \\
\hline 3 & 3 & $-2,28$ \\
\hline 0 & 4 & 24,468 \\
\hline 1 & 4 & 5,238 \\
\hline 2 & 4 & $-4,54$ \\
\hline 3 & 4 & $-4,866$ \\
\hline 4 & 4 & 4,26 \\
\hline 0 & 5 & 27,32 \\
\hline 1 & 5 & 5,936 \\
\hline 2 & 5 & $-5,996$ \\
\hline 3 & 5 & $-8,476$ \\
\hline 4 & 5 & $-1,504$ \\
\hline 8 & 5 & 120,904 \\
\hline 0 & 6 & 29,148 \\
\hline 1 & 6 & 5,61 \\
\hline 2 & 6 & $-8,476$ \\
\hline 3 & 6 & $-13,11$ \\
\hline 4 & 6 & $-8,292$ \\
\hline 0 & 7 & 29,952 \\
\hline 1 & 7 & 4,26 \\
\hline 2 & 7 & $-11,98$ \\
\hline 3 & 7 & $-18,768$ \\
\hline 4 & 7 & $-16,104$ \\
\hline
\end{tabular}


Table 20 Iteration 9 (continuation

from table 19)

\begin{tabular}{|c|c|c|}
\hline ICAs & PCAs & L\&OH CPU (delta) \\
\hline 0 & 7 & 29,952 \\
\hline 1 & 7 & 4,26 \\
\hline 2 & 7 & $-11,98$ \\
\hline 3 & 7 & $-18,768$ \\
\hline 4 & 7 & $-16,104$ \\
\hline 0 & 8 & 29,732 \\
\hline 1 & 8 & 1,886 \\
\hline 2 & 8 & $-16,508$ \\
\hline 3 & 8 & $-25,45$ \\
\hline 4 & 8 & $-24,94$ \\
\hline 5 & 8 & $-14,978$ \\
\hline 6 & 8 & 4,436 \\
\hline 7 & 8 & 33,302 \\
\hline 0 & 9 & 28,488 \\
\hline 1 & 9 & $-1,512$ \\
\hline 2 & 9 & $-22,06$ \\
\hline 3 & 9 & $-33,156$ \\
\hline 4 & 9 & $-34,8$ \\
\hline 5 & 9 & $-26,992$ \\
\hline 0 & 10 & 26,22 \\
\hline 1 & 10 & $-5,934$ \\
\hline 2 & 10 & $-28,636$ \\
\hline 3 & 10 & $-41,886$ \\
\hline 4 & 10 & $-45,684$ \\
\hline 5 & 10 & $-40,03$ \\
\hline 0 & 11 & 22,928 \\
\hline 1 & 11 & $-11,38$ \\
\hline 2 & 11 & $-36,236$ \\
\hline 3 & 11 & $-51,64$ \\
\hline 4 & 11 & $-57,592$ \\
\hline 5 & 11 & $-54,092$ \\
\hline 0 & 12 & 18,612 \\
\hline 1 & 12 & $-17,85$ \\
\hline 2 & 12 & $-44,86$ \\
\hline 3 & 12 & $-62,418$ \\
\hline 4 & 12 & $-70,524$ \\
\hline 5 & 12 & $-69,178$ \\
\hline
\end{tabular}

\section{References}

A. Delios, Beamish PW (2001). Survival and profitability: the roles of experience and intangible assets in foreign subsidiary performance. Academy of Management Journal 44 (50) 1028-1038.

Bansal A, Kauffmann RJ, Weitz RR (1993). Comparing the performance of regression and neural networks as data quality varies: a business value approach. Journal of Management Information Systems. Vol. 10 No. 1 pp. 11-32.

Bedessi S, Lisi S (2011). AHP, ANP and ANN: Technical differences, conceptual connections, hybrid models. Proceedings of the International Symposium on the Analytic Hierarchy Process.
Becketti, S. 2013. Introduction to Time Series Using Stata. College Station, TX: Stata Press.

Boj JJ, Rodriguez-Rodriguez R and Alfaro-Saiz JJ (2014). An ANP-Multi-criteria-based methodology to link intangible assets and organizational performance in a Balanced Scorecard context. Decision Support Systems, 68, 98-110. Available on-line at: www.elsevier.com/locate/ dss.

Box GE, Jenkins GC, Reinsel GC (2008). Time Series Analysis Forecasting and Control. New York: John Wiley and Sons. 
Brodersen RM, Yanoski D, Mason K, Apthorp H, Piscatelli J (2017). Overview of selected state policies and supports related to K-12 competency-based education. National Center for Education Evaluation and Regional Assistance. Institute of Education Sciences. U.S. Department of Education. Available at Google Scholar.

Chang SC, Chen SS, Lai JH (2008), The effect of alliance experience and intellectual capital on the value creation of international strategic alliances, Omega-International Journal of Management Science, 36, 298-316.

Chytas P, Glykas M, Valiris G (2011). A proactive balanced scorecard. International Journal of Information Management 31 (2011) 460 - 468. Available on-line at: www. elsevier.com/locate/ijinfomgt.

Cooper, D. J., Ezzamel, M., \& Qu, S. Q. (2017). Popularizing a management accounting idea: The case of the balanced scorecard. Contemporary Accounting Research, 34(2), 991-1025.

Dickey, D. A., and W. A. Fuller. 1979. Distribution of the estimators for autoregressive time series with a unit root. Journal of the American Statistical Association 74: 427-431.

Dincer, H., Hacioglu, U., \& Yuksel, S. (2016). Balanced scorecard-based performance assessment of Turkish banking sector with analytic network process. International Journal of Decision Sciences \& Applications-IJDSA, 1(1), 1-21.

Dumay, J. (2014). 15 years of the journal of intellectual capital and counting: a manifesto for transformational IC research. Journal of Intellectual Capital, 15(1), 2-37.

Göleç, A. (2015). A relationship framework and application in between strategy and operational plans for manufacturing industry. Computers \& Industrial Engineering, 86, 83-94.

Hoque, Z. (2014). 20 years of studies on the balanced scorecard: trends, accomplishments, gaps and opportunities for future research. The British accounting review, 46(1), 33-59.

Johnstone SM \& Soares L (2014). Principles for Developing Competency-Based Education Programs. Change: The Magazine of Higher Learning, 46:2, 12-19, DOI: http:// dx.doi.org/10.1080/00091383.2014.896705

Jurczak J (2008). Intellectual Capital Measurement Methods. Organization and Management in Industry 1 (1) 3745. DOI: $10.2478 / v 10061-008-0005-y$
Kaplan R S (2009). Conceptual Foundations of the Balanced of the Balanced Scorecard. Handbooks of Management Accounting Research. DOI: 10.1016/S175413243(07)03003-9

Kaplan R S, Norton D P (1992). The Balanced Scorecard - Measures that Drive Performance. Harvard Business Review, 70 (1) 71-79.

Kaplan R S, Norton D P (1996a). Using the Balanced Scorecard as a Strategic Management System. Harvard Business Review, January-February (1996) pp. 35-48.

Kaplan R S, Norton D P (1996b). The balanced scorecardtranslating strategy into action. Boston, MA: Harvard Business School Press.

Kang, N., Zhao, C., Li, J., \& Horst, J. A. (2016). A Hierarchical structure of key performance indicators for operation management and continuous improvement in production systems. International Journal of Production Research, 54(21), 6333-6350.

Kaufmann L, Schneider Y (2004). Intangibles: a synthesis of current research. Journal of Intellectual Capital 5 (3) 366-388.

McGaughey SL (2002), Strategic interventions in intellectual assets flows, Academy of Management Review 27 (2) 248-274.

Minitab Web Page: http://www.minitab.com

Mirabile RJ (1997). Everything you wanted to know about competency modelling. Training \& Development: Aug 1997; 51, 8; ABI/INFORM Collection pg.73

Morard, B., Stancu, A., \& Jeannette, C. (2013). Time evolution analysis and forecast of key performance in a balanced scorecard. Global Journal of Business Research,7(2), 9-27.

Morcke AM, Dornan T, Eika B (2013). Outcome (competency) based education: an exploration or its origins, theoretical basis, and empirical evidence. Adv in Helth Sci Educ (2013) 18:851-863. DOI 10.1007/s10459-0129405-9.

Nahapiel J, Ghoshal S (1998). Social Capital, intellectual capital, and the organizational advantage. Academy of Management Review 23 (2) 242-266.

Noerreklit H (2000). The balance on the balanced scorecarda critical analysis of some of its assumptions. Management Accounting Research, 11, 65-88. Available online at http://www.idealibrary.com 
Noerreklit H, Schoenfeld HM W (2000). Controlling Multinational Companies: An attempt to Analyze Some Unresolved Issues. The International Journal of Accounting, Vol. 35, No. 3, pp. 415-430.

Norman G, Norcini J, Bordage G (2014). Competency-Based Education: Milestones or Millstones? Journal of Graduate Medical Education. Vol. 6, No. 1, pp. 1-6. DOI: http://dx.doi.org/10.4300/JGME-D-13-00445.1

Otley D (1999). Performance management: a framework for management control systems research. Management Accounting Research, 10, 363 - 382.

Pijl-Zieber EM, Barton S, Konkin J, Awsoga O, Caine V (2014). Competence and competency-based nursing education: Finding our way through the issues. Nuse Education Toda 34 (2014) 676-678.

Rabbani, A., Zamani, M., Yazdani-Chamzini, A., \& Zavadskas, E. K. (2014). Proposing a new integrated model based on sustainability balanced scorecard (SBSC) and MCDM approaches by using linguistic variables for the performance evaluation of oil producing companies. Expert Systems with Applications, 41(16), 7316-7327.

Rodriguez-Rodriguez R, Alfaro-Saiz JJ, Ortiz-Bas A (2009). Quantitative relationships between key performance indicators supporting decision-making processes. Computers in Industry, 60 (2) pp. 104-113. Doi: 10.1016/j. compind.2008.09.002

Rodriguez-Rodriguez R, Alfaro-Saiz JJ, Verdecho MJ (2014). A Performance Measurement System to Manage CEN Operations, Evolution and Innovation. L.M. Camarinha-Matos and H. Afsarmanesh (Eds.): PRO-VE 2014, IFIP AICT 434, pp. 569-576.

Sanchez-Marquez R, Albarracin-Guillem JM, Vicens-Salort E (Under Review). Proposal of a systemic methodology for the assessment and selection of Balanced Scorecard Key Performance Indicators in Manufacturing Environment. Central European Journal of Operations Research.
Stata Web Page: http://www.stata.com

Stewart TA, Ruckdeschel C (1998). Intellectual Capital: The New Wealth of Organizations. Perf. Improv., 37: 56-59. doi:10.1002/pfi.4140370713

Sturgis C, Patrick S, Pittenger L (2011). It's not a matter of time: Highlights from the 2011 Competency-Based Learning Summit. International Association for K-12 Online Learning - ERIC. https://eric.ed.gov /?id=ED537332

Teece DJ (2000). Managing Intellectual Capital: Organizational, Strategic, and Policy Dimensions. Oxford: Oxford University Press.

Ten Cate O (2013). Competency-Based Education, Entrustable Professional Activities, and the Power of Language. Journal of Graduate Medical Education, 5, pp. 6-7. DOI: http://dx.doi.org/10.4300/JGME-D-12-00381.1

Varmazyar M, Dehghanbaghi M., \& Afkhami M (2016). A novel hybrid MCDM model for performance evaluation of research and technology organizations based on BSC approach. Evaluation and program planning 58, 125140.

Verdecho MJ, Alfaro-Saiz JJ, Rodriguez-Rodriguez R (2014). A Performance Management Framework for Managing Sustainable collaborative enterprise Networks. L.M. Camarinha-Matos and H. Afsarmanesh (Eds.): PRO-VE 2014, IFIP AICT 434, pp. 546-554.

Wu JP, Wei S (1989). Time series analysis. Hunan Science and Technology Press, ChangSha. Available online at: $\quad$ http://www2.geog.ucl.ac.uk/ mdisney/teaching/ GEOGG121/time series/GEOGG121 5 TimeSeries Wu.pdf. Retrieved: January 20, 2018.

Zhijun, L. I. N., Zengbiao, Y. U., \& Zhang, L. (2014). Performance outcomes of balanced scorecard application in hospital administration in China. China Economic Review, 30, 1-15. 